\title{
RESÍDUOS SÓLIDOS URBANOS: UM ESTUDO DE CASO NA CIDADE DE PEROBAL - PR
}

\author{
Sandra dos Santos Ornellas ${ }^{1}$ \\ Bruna Fernanda Barbado Migliozzi ${ }^{2}$ \\ Norma Barbado 3
}

\begin{abstract}
RESUMO
A gestão dos resíduos sólidos urbanos pode influenciar na qualidade de vida da população e na preservação do meio ambiente. Nesse contexto, este estudo teve como objetivo principal diagnosticar e refletir sobre o processo de gestão dos resíduos sólidos urbanos de Perobal, situado no noroeste do Paraná, Brasil. Para tanto, realizou-se um estudo de caso, de caráter exploratório e descritivo, organizado em três etapas: 1- levantamento de dados primários e secundários; 2- exploração do material; 3- tratamento dos resultados. Os dados obtidos demonstraram que, apesar dos bons resultados nos indicadores de qualidade de vida, são necessárias as seguintes providências no gerenciamento dos resíduos sólidos: adequações no Plano de Gerenciamento Integrado de Resíduos Sólidos do município; exigência de implantação e fiscalização de Planos de Gerenciamento de Resíduos Sólidos nos estabelecimentos comerciais; adequações no aterro sanitário para melhor organização dos resíduos e realização de processos de compostagem; projetos de educação ambiental devem ser desenvolvidos em ambiente formal e não formal, no intuito de informar e sensibilizar a população quanto à importância da separação correta dos resíduos sólidos.
\end{abstract}

Palavras-chave: Educação Ambiental. Qualidade de Vida. Coleta Seletiva.

\footnotetext{
${ }^{1}$ Licenciada em Ciências Biológicas pelo Instituto Federal do Paraná (IFPR) Campus Umuarama. Email: sandra ornella@hotmail.com

2 Graduada em Direito pela Universidade Paranaense (UNIPAR), Umuarama - PR. E-mail: brunafernandam98@gmail.com

${ }^{3}$ Licenciada em Biologia, mestre em Educação, doutora em Agronomia, docente do Instituto Federal do Paraná (IFPR) Campus Umuarama. E-mail: norma.barbado@ifpr.edu.br
}

R. gest. sust. ambient., Florianópolis, v. 10, n. 2, p. 209-229, jun. 2021. 


\title{
URBAIN SOLID WASTE: A CASE STUDY IN THE PEROBAL - PR CITY
}

\begin{abstract}
The management of urban solid waste can influence the quality of life of the population and the preservation of the environment. In this context, this study aimed to diagnose and reflect the urban solid waste management process in Perobal, located in the North West of the state of Paraná, Brazil. For this, a case study was carried out, with na exploratory and descriptive aspect, organized in three stages: 1- survey of primary and secondary data; 2- exploration of the material; 3- treatment of results. The data obtained showed that, despite the good results in the quality of life indicators, the following measures are required in solid waste management: adjustments to the municipality's Integrated Solid Waste Management Plan; requirement to implement and supervise solid waste management plans in commercial establishments; landfill adjustments for better waste organization and composting processes; environmental education projects and actions must be developed, in a formal and non-formal environment, to inform and raise awareness among the population about the importance of correct separation of solid waste.
\end{abstract}

Keywords: Solid Waste Management. Environmental Education. Quality of Life. Selective Collect.

\section{INTRODUÇÃO}

A crescente geração de resíduos sólidos urbanos (RSU) tornou-se alvo de muita discussão nos últimos tempos. Buscando encontrar caminhos que ajudem a minimizar os impactos causados pela destinação inadequada dos mesmos, é notável a preocupação da sociedade e dos gestores públicos em relação à preservação ambiental (GOUVEIA, 2012), mas ainda falta muito para que a conscientização, de fato, aconteça. Esta preocupação é resultado do mau gerenciamento e da grande quantidade de resíduos sólidos, causando muitos problemas ao meio ambiente. Isso se deve a vários fatores como: êxodo rural, industrialização, urbanização acelerada, crescimento da população (GIACCOM-RIBEIRO; MENDES, 2018), mudança no padrão de consumo, desenvolvimento humano (DEUS; BATTISTELLE; SILVA, 2017), entre outros.

Segundo a Organização das Nações Unidas (ONU), a atual geração de resíduos no mundo gira em torno de 12 bilhões de toneladas por ano e, até o final de 2020, o volume previsto é de 18 bilhões de toneladas por ano (ONU, 2019). Nesse sentido, um levantamento realizado pela Associação Brasileira de Empresas de Limpeza Pública e Resíduos Especiais (ABRELPE, 2020) mostra que o volume de RSU gerado no Brasil foi de 60 milhões de toneladas no ano de 2010, 6,8\% superior

R. gest. sust. ambient., Florianópolis, v. 10, n. 2, p. 209-229, jun. 2021. 
ao ano anterior. Em 2017, em relação a 2016, o aumento foi de 1\%, passando de 212.753 para 214.868 toneladas por dia. Vale ressaltar que o custo financeiro e ambiental para gerenciar esse expressivo volume é enorme. A ONU estima que de $20 \%$ a $30 \%$ dos orçamentos das cidades são despendidos na coleta e disposição dos resíduos (DIAS, 2012).

No Brasil, mesmo que a Agenda-21 tenha formalizado mundialmente a preocupação com a gestão dos RSU, o tema só se destacou a partir da instituição da Política Nacional de Resíduos Sólidos (PNRS), pela Lei Federal No 12.305/2010 (RODRIGUES; MARIN; ALVARENGA, 2017), com o Decreto Federal № 7.4040/2010. Essa legislação tem como objetivo principal minimizar impactos causados no meio ambiente pelos RSU e determinar a responsabilidade de gestão adequada pelos seus geradores, o poder público e consumidores finais (BRASIL, 2010). Assim, destinatários dos RSU, pessoas físicas ou jurídicas, de direito público ou privado, são responsáveis, direta ou indiretamente, pela geração dos resíduos por meio de suas atividades, incluindo o consumo e as ações relacionadas à gestão integrada ou ao seu gerenciamento (RAUBER, 2011). Vale ressaltar que os catadores de material reciclável são atores principais para o sucesso da PNRS, lei que apresenta vários instrumentos essenciais ao enfrentamento de problemas oriundos da má gestão dos RSU (SILVA; MARCOMIN, 2020).

A PNRS destaca ainda que os governos, municipais e estaduais, ficam encarregados de delinear metas para redução dos RSU, com a seguinte ordem de prioridade: não geração, redução, reutilização, reciclagem, tratamento dos resíduos sólidos e disposição final ambientalmente adequada dos rejeitos (RODRIGUES; MARIN; ALVARENGA, 2017). Quando bem planejado, um Plano Municipal de Gerenciamento de Resíduos Sólidos (PMGRS) é uma ferramenta estratégica para garantir o princípio da eficácia ambiental, essencial para atender a PNRS e, ainda, para ter acesso aos recursos da União destinados a atividades de limpeza urbana e manejo de RSU (PINTO; NASCIMENTO, 2017).

Para o sucesso de um PMGRS, uma de suas premissas deve ser a Educação Ambiental (EA), incluída na Constituição Federal de 1988, de forma explícita no Art. 225, inciso VI, no intuito de "promover a educação ambiental em todos os níveis de ensino e a conscientização pública para a preservação do meio ambiente" (BRASIL, 2016). Para regulamentar esse comando institucional, a Lei da Educação Ambiental (Lei Federal № 9.795/1999), institui em seu artigo primeiro:

R. gest. sust. ambient., Florianópolis, v. 10, n. 2, p. 209-229, jun. 2021. 
Entendem-se por educação ambiental os processos por meio dos quais o indivíduo e a coletividade constroem valores sociais, conhecimentos, habilidades, atitudes e competências voltadas para a conservação do meio ambiente, bem de uso comum do povo, essencial à sadia qualidade de vida e sua sustentabilidade (BRASIL, 1999).

Somente por meio da mudança de hábitos e valores da população, haverá contribuição adequada na gestão dos resíduos sólidos (JARDIM; YOSHIDA; MACHADO FILHO, 2012). Nessa direção, Carvalho (2004) cita que a EA contribui significativamente no enfrentamento dos problemas ambientais, atuando em diversos saberes e produzindo concepções, reflexões, métodos e experiências visando a construção de novos fundamentos de conhecimento e valores ecológicos para as presentes e futuras gerações. Para Bagnolo (2010), a maioria das pessoas já conhece a realidade e as evidências dos problemas ambientais e sabe da necessidade de preservar o meio ambiente. Assim, a EA pode ser um instrumento para sensibilizar e propiciar uma mudança da sociedade, promovendo ações éticas, políticas e emancipadoras (SILVA; MARCOMIN, 2020).

Vale destacar que o PMGRS deve prever ações de logística reversa (LR), já prevista no art. 4ํ da Resolução CONAMA № 401/2008. Ela cita a obrigatoriedade dos estabelecimentos comerciais no recebimento das pilhas e baterias dos usuários, destinando esses resíduos aos fabricantes (BRASIL, 2008). Segundo a PNRS, a LR favorece o reaproveitamento dos resíduos em seu ciclo ou em outros ciclos produtivos, ou ainda sua destinação final ambientalmente adequada (BRASIL, 2010).

Essa gestão integrada de RSU deve ser avaliada com frequência no município (SANTIAGO; DIAS, 2012), fiscalizando também a presença do plano de gerenciamento de resíduos sólidos (PGRS) em todos os estabelecimentos. O PGRS é um documento que deve apresentar o diagnóstico e o gerenciamento dos resíduos, desde sua geração, passando pelo armazenamento, até seu destino final, com propostas de redução desta produção e plano de EA (BRASIL, 2010). Diante do exposto, este estudo teve como objetivo principal fazer um diagnóstico e promover a reflexão sobre o processo de gestão dos RSU do município de Perobal, PR, Brasil. Os objetivos secundários foram: caracterizar o aterro sanitário de Perobal - PR; confrontar informações obtidas por meio da secretaria municipal de meio ambiente de Perobal - PR, do catador responsável pela destinação final de resíduos recicláveis e de representantes da população perobalense sobre a gestão dos RSU.

R. gest. sust. ambient., Florianópolis, v. 10, n. 2, p. 209-229, jun. 2021. 


\section{METODOLOGIA}

O município de Perobal, situado no noroeste do Paraná, Brasil, distante aproximadamente $600 \mathrm{~km}$ da capital Curitiba, foi fundado oficialmente como distrito em 1961 e emancipado em 29 de abril de 1997. Possui aproximadamente 6.127 habitantes e uma extensão de 407,848 km² (IPARDES, 2019). Sua economia se baseia na agroindústria e na agricultura, destacando-se a produção de cana-deaçúcar, soja e milho (PMGIRS, 2013).

Este estudo de caso (Quadro 1) realizado em 2019, apresentou o caráter exploratório e descritivo, utilizando-se métodos de coleta de informações padronizados (PRODANOV; FREITAS, 2013) como uma de suas premissas. A pesquisa foi organizada em três fases (Quadro 1), incorporando elementos de origem quantitativa e qualitativa (pesquisa mista). As entrevistas (Quadro 1) foram realizadas de forma direta e semiestruturada, conforme recomenda Kauark, Manhães e Medeiros (2010). A amostragem intencional de moradores de Perobal - PR foi composta por 80 pessoas. Dentre elas, 60 participaram, voluntariamente, de uma palestra interativa a respeito do gerenciamento de RSU. Esta ação ocorreu no Centro de Referência em Assistência Social (CRAS), com grupos de idosos e funcionários do setor, potenciais agentes multiplicadores das informações. Buscando contemplar todos os bairros da cidade, mais 20 pessoas foram entrevistadas por meio das redes sociais, em grupos de moradores de Perobal - PR. As principais questões levantadas aos moradores foram: 1) Em sua residência a coleta de resíduos (lixo) acontece regularmente? 2) Você separa os resíduos em sua residência e entrega separado para a coleta seletiva? Como? Por que? 3) O que você faz com lâmpadas, baterias e pilhas que não funcionam mais? 4) Você já visitou o aterro sanitário de Perobal? 5) Você já observou resíduos (lixo) jogados em locais inadequados na cidade de Perobal? Onde?

Quadro 1- Descrição das fases do estudo de caso realizado em Perobal - PR, sobre a gestão dos resíduos sólidos urbanos, em 2019.

\begin{tabular}{|c|c|c|c|}
\hline \multirow{7}{*}{$\begin{array}{c}1^{a} \\
\text { fase }\end{array}$} & \multirow{3}{*}{ Dados primários } & \multirow{3}{*}{ Entrevista* } & $\begin{array}{c}\text { Secretário de Agricultura e Meio } \\
\text { Ambiente }\end{array}$ \\
\hline & & & Catador de Recicláveis \\
\hline & & & Moradores \\
\hline & \multirow{3}{*}{ Dados secundários } & \multirow{2}{*}{$\begin{array}{c}\text { Pesquisa } \\
\text { documental* }\end{array}$} & PMGIRS de Perobal \\
\hline & & & Plano Diretor de Perobal \\
\hline & & $\begin{array}{l}\text { Pesquisa } \\
\text { Bibliográfica }\end{array}$ & Livros e artigos científicos \\
\hline & \multicolumn{3}{|c|}{ Leitura flutuante } \\
\hline \multirow{2}{*}{$\begin{array}{c}2^{a} \\
\text { fase }\end{array}$} & \multirow{2}{*}{ Exploração do Material } & \multirow{2}{*}{ Categorização** } & Qualidade de vida \\
\hline & & & Aterro Sanitário \\
\hline
\end{tabular}

R. gest. sust. ambient., Florianópolis, v. 10, n. 2, p. 209-229, jun. 2021. 


\begin{tabular}{|c|c|c|c|}
\hline & & & Coleta Seletiva \\
\hline $\begin{array}{c}\mathbf{3}^{\mathbf{a}} \\
\text { fase }\end{array}$ & $\begin{array}{c}\text { Tratamento dos } \\
\text { Resultados }\end{array}$ & \multicolumn{2}{c|}{ Dados qualitativos e quantitativos: Análise de Conteúdo** } \\
\multicolumn{2}{|c|}{ Fonte: Elaborado pelas autoras com base em *Kauark, Manhães e Medeiros (2010) e ${ }^{\star \star}$ Bardin (2016). }
\end{tabular}

Os dados secundários, citados no Quadro 1, foram obtidos por meio de pesquisa documental, utilizando-se o Plano Municipal de Gerenciamento Integrado de Resíduos Sólidos (PMGIRS) (PEROBAL, 2018) e Plano Diretor do Município de Perobal - PR (PEROBAL, 2011). Por meio de pesquisa bibliográfica, foi possível elencar dados de relevantes indicadores de qualidade de vida do município pesquisado (Perobal), da capital do estado (Curitiba), do estado (Paraná) e do país (Brasil). Além disso, foram consultadas as legislações pertinentes ao estudo nas seguintes páginas: Compromisso Empresarial para Reciclagem (CEMPRE), Conselho Nacional do Meio Ambiente (CONAMA), Instituto Brasileiro de Geografia e Estatística (IBGE), Instituto Paranaense de Desenvolvimento (IPARDES), Programa das Nações Unidas para o Desenvolvimento (PNUD) e Organização das Nações Unidas (ONU). Ainda na primeira etapa, conforme recomenda Bardin (2016), houve leitura "flutuante", ou seja, a partir do primeiro contato com os documentos e seleção do material a ser avaliado visando contemplar o objetivo do trabalho.

A categorização, indicada na segunda fase da pesquisa, foi realizada para traçar o perfil da população no panorama do gerenciamento de RSU de Perobal - PR, comparando com dados da capital Curitiba, do estado do Paraná e do país, Brasil.

$\mathrm{Na}$ terceira e última fase da pesquisa, houve o tratamento dos resultados, com inferências e interpretação dos dados qualitativos e quantitativos avaliados por meio da técnica de análise de conteúdo (BARDIN, 2016). Nessa metodologia, na análise quantitativa as informações são obtidas a partir da frequência das características do conteúdo. Já na análise qualitativa, as considerações são realizadas a partir da presença ou ausência de uma característica de conteúdo ou de um conjunto de características num determinado fragmento de mensagem.

\section{RESULTADOS E DISCUSSÃO}

\subsection{Qualidade de Vida}

A gestão dos resíduos sólidos urbanos (RSU) influencia diretamente a qualidade de vida da população, seu mau gerenciamento pode desencadear problemas relacionados à saúde devido ao seu potencial de contaminação e facilitador da proliferação de vetores (BOHRER et al., 2019). Na maioria das vezes, tais

R. gest. sust. ambient., Florianópolis, v. 10, n. 2, p. 209-229, jun. 2021. 
problemas ocorrem em regiões urbanas periféricas e em áreas de baixo valor econômico (BESEN, 2011). Assim, a disposição inadequada de RSU é um importante fator de risco para a saúde coletiva (ZANATA; SOBRINHO; RODRIGUES, 2010). Para melhor compreender a dinâmica de qualidade de vida da população de Perobal - PR foi fundamental observar alguns indicadores (Tabela 1) que, direta e/ou indiretamente, se relacionam com a questão dos RSU.

Tabela 1 - Variáveis quantitativas. Número de habitantes (NI), índice de GINI da renda domiciliar per capita (GINI), produto interno bruto per capita (PIB) e índice de desenvolvimento humano (IDH) do município de Perobal - PR, comparados à capital do Estado (Curitiba) e às médias estadual e nacional.

\begin{tabular}{l|c|c|c|c}
\hline & Perobal & Curitiba & Paraná & Brasil \\
\hline NI & $\pm 6.127^{2}$ & $\pm 1.933 .1052^{2}$ & $\pm 11.433 .957^{2}$ & $\pm 210.147 .125^{2}$ \\
GINI & $0,4087^{2}$ & $0,5652^{2}$ & $0,5416^{2}$ & $0,6086^{2}$ \\
PIB & $25.413^{1}$ & $44.385^{1}$ & $37.2211^{1}$ & $31.702^{1}$ \\
IDH & $0,713^{2}$ & $0,823^{2}$ & $0,749^{2}$ & $0,755^{2}$ \\
\hline
\end{tabular}

Fonte: ${ }^{1}$ Ipardes (2019); ${ }^{2}$ IBGE (2010).

Em relação ao índice de GINI, Cantero Dorsa e Constantino (2018) afirmam que, quanto mais próximo de zero, menor é a desigualdade social, com melhor distribuição de renda. Nesse quesito, o índice do município de Perobal - PR encontrase melhor do que o da capital Curitiba, do estado do Paraná e do país (Tabela 1). Esse indicador, criado pelo matemático italiano Conrado Gini, aponta a diferença entre os rendimentos dos mais pobres e dos mais ricos (IPEA, 2004), sendo muito conhecido e aplicado (NEDER, 2013).

Quanto ao produto interno bruto (PIB) per capita, a média do município de Perobal - PR encontra-se inferior à da capital Curitiba (em $5^{\circ}$ lugar no país), assim como da estadual e nacional (Tabela 1), considerando-se o crescimento acumulado de $1 \%$ em quatro trimestres (IBGE, 2019). Nesse sentido, Macedo e Porto (2018) relatam que o PIB municipal é a principal referência a respeito da dinâmica econômica regional, com disponibilidade anual. Os autores relatam que as diferenças do PIB entre os municípios determinam a possibilidade de oferta de serviços públicos que contribuem para melhor qualidade de vida da população.

Segundo o programa das nações unidas para o desenvolvimento, o índice de desenvolvimento humano (IDH) entre 0,700 e 0,799 é considerado alto (PNUD, 2014). Assim, tanto o município de Perobal, quanto seu estado (Paraná) e o país (Brasil) possuem o IDH alto (Tabela 1). Porém, essas médias comparadas à capital do estado (Curitiba), com IDH 0,823, considerado muito alto (PNUD, 2014), ainda há o que

R. gest. sust. ambient., Florianópolis, v. 10, n. 2, p. 209-229, jun. 2021. 
melhorar nesse quesito. De acordo com Cantero Dorsa e Constantino (2018), o IDH foi o primeiro índice social mundial que possibilitou comparar o ranking de áreas fundamentais na qualidade de vida, favorecendo o pensar global, agir local. Esse índice pode ser considerado um reflexo do desenvolvimento econômico e sustentável, já que considera a renda PIB per capita, a saúde (expectativa média de vida) e a educação (escolaridade).

Os dados acima citados são muito relevantes neste estudo, já que a problemática da destinação final dos resíduos sólidos está ligada às dificuldades socioeconômicas e à distribuição de renda. Esses fatores são diretamente relacionados com a capacidade de gestão dos municípios, nem sempre ligados ao território dos mesmos (SCHNEIDER; RIBEIRO; SALOMONI, 2013). Vale ressaltar que, o município de Perobal - PR é considerado pequeno, com o PIB per capita considerado baixo. Nesse sentido, Campos (2012) relata que, famílias com melhores condições, municípios maiores e países mais ricos possuem indicadores de geração per capita de RSU superiores às famílias mais pobres, pequenos municípios e países em desenvolvimento. No entanto, os dados deste estudo revelam que, mesmo considerado como município pequeno, a geração de RSU per capita de Perobal - PR está muito alta. Esses dados serão demonstrados do decorrer deste artigo.

\subsection{Aterro Sanitário}

O aterro sanitário de Perobal - PR foi construído no ano de 2012 e está localizado na Estrada Velha, Km 3. Seu projeto inicial considerava as características quanto ao crescimento populacional, à geração de resíduos sólidos, o sistema de limpeza urbana e a manutenção do aterro (OLIVEIRA; PIRES; NUNES, 2016). Assim, definiu-se a construção de nove valas para descarte dos resíduos com formato trapezoidal. As dimensões estão descritas na Tabela 2. O volume útil total do conjunto foi estimado em $36.673,38 \mathrm{~m}^{3}$.

Tabela 2 - Descrição do projeto do aterro sanitário de Perobal - PR.

\begin{tabular}{c|c|c|c|c|c|c}
\hline Valas & $\begin{array}{c}\text { Comprimento } \\
\text { topo da vala } \\
(\mathbf{m})\end{array}$ & $\begin{array}{c}\text { Largura } \\
\text { topo da } \\
\text { vala }(\mathbf{m})\end{array}$ & $\begin{array}{c}\text { Comprimento } \\
\text { base da vala } \\
(\mathbf{m})\end{array}$ & $\begin{array}{c}\text { Largura } \\
\text { base da } \\
\text { vala }(\mathbf{m})\end{array}$ & $\begin{array}{c}\text { Profundidade } \\
(\mathbf{m})\end{array}$ & $\begin{array}{c}\text { Volume } \\
\text { útil por } \\
\text { vala }\left(\mathbf{m}^{3}\right)\end{array}$ \\
\hline 01 & 45,00 & 13,00 & 38,00 & 6,00 & 4,00 & $1.557,90$ \\
02 & 90,00 & 13,00 & 83,00 & 6,00 & 4,00 & $2.537,90$ \\
03 & 135,00 & 13,00 & 128,00 & 6,00 & 4,00 & $4.653,94$ \\
04 & 135,00 & 13,00 & 128,00 & 6,00 & 4,00 & $4.653,94$ \\
05 & 135,00 & 13,00 & 128,00 & 6,00 & 4,00 & $4.653,94$ \\
06 & 135,00 & 13,00 & 128,00 & 6,00 & 4,00 & $4.653,94$ \\
07 & 135,00 & 13,00 & 128,00 & 6,00 & 4,00 & $4.653,94$
\end{tabular}

R. gest. sust. ambient., Florianópolis, v. 10, n. 2, p. 209-229, jun. 2021. 


\begin{tabular}{c|c|c|c|c|c|c}
08 & 135,00 & 13,00 & 128,00 & 6,00 & 4,00 & $4.653,94$ \\
09 & 135,00 & 13,00 & 128,00 & 6,00 & 4,00 & $4.653,94$ \\
\hline \multicolumn{2}{l}{ Volume útil total do projeto do aterro sanitário de Perobal - PR $\left(\mathrm{m}^{3}\right)$} \\
\hline
\end{tabular}

Fonte: Perobal, 2012.

A partir de dados iniciais do IBGE, Oliveira, Pires e Nunes (2016) determinaram os valores estimados de progressão da população perobalense a cada 5 anos, consequentemente, da geração de resíduos (Tabela 3).

Tabela 3 - Projeção de volume anual de resíduos a serem produzidos por moradores de Perobal - PR a cada 5 anos.

\begin{tabular}{|c|c|c|c|c|c|c|}
\hline Ano & $\begin{array}{l}\text { População } \\
\text { estimada } \\
\text { com } \\
\text { progressão } \\
\text { aritmética } \\
\text { (hab) }\end{array}$ & $\begin{array}{c}\text { Volume } \\
\text { anual de } \\
\text { lixo } \\
\text { progressão } \\
\text { aritmética } \\
\left(\mathrm{m}^{3}\right)\end{array}$ & $\begin{array}{c}\text { Volume } \\
\text { acumulado } \\
\text { de lixo } \\
\left(\mathrm{m}^{3}\right)\end{array}$ & $\begin{array}{l}\text { População } \\
\text { estimada } \\
\text { com } \\
\text { progressão } \\
\text { geométrica } \\
\text { (hab) }\end{array}$ & $\begin{array}{c}\text { Volume } \\
\text { anual de } \\
\text { resíduos } \\
\text { (progressão } \\
\text { geométrica } \\
\left(\mathrm{m}^{3}\right)\end{array}$ & $\begin{array}{c}\text { Volume } \\
\text { acumulado } \\
\text { de } \\
\text { resíduos } \\
\left(\mathrm{m}^{3}\right)\end{array}$ \\
\hline 2013 & 5923 & $2.160,8$ & $2.160,8$ & 5923 & $2.160,80$ & $2.160,80$ \\
\hline 2018 & 6100 & $2.226,5$ & $11.160,58$ & 6100 & $2.226,50$ & $11.160,58$ \\
\hline 2023 & 6275 & $2.290,01$ & $22.396,85$ & 6282 & $2.292,93$ & $22.490,18$ \\
\hline 2028 & 6450 & $2.354,25$ & $36.126,43$ & 6468 & $2.360,82$ & $36.156,67$ \\
\hline 2033 & 6625 & $2.418,12$ & $48.089,29$ & 6660 & $2.430,90$ & $48.215,27$ \\
\hline
\end{tabular}

Fonte: Oliveira, Pires e Nunes (2016) adaptado.

De acordo com a NBR 13896/1997, recomenda-se para a construção de aterros sanitários uma vida útil mínima de 10 anos, com monitoramento de, no mínimo, por mais 10 anos após ser encerrada a disposição de resíduos no local (ABNT, 1997). O aterro sanitário de Perobal - PR, com base nos dados da Tabela 3, terá sua capacidade esgotada no ano de 2028, ou seja, sua vida útil foi estimada em 15 anos (OLIVEIRA; PIRES; NUNES, 2016). Neste local, há uma lagoa de chorume em que, quando está acima do nível máximo permitido, promove-se a recirculação fechada, bombeando-o novamente para a vala, corroborando para a decomposição dos resíduos. Nesse sentido, Oliveira, Pires e Nunes (2016) relatam a ausência de manutenção no sistema de drenagem, resultando em acúmulo de chorume da vala de disposição de resíduos. Os autores calcularam o Índice de Qualidade de Aterro de Resíduos (IQR) deste local, resultando em 6,53, caracterizando-o como em condições controladas.

Em relação à amostra da população que respondeu se já havia visitado o aterro sanitário de Perobal, obteve-se um resultado de apenas $5 \%$ com esta afirmação. Esse conhecimento é fundamental. Marques e Xavier (2019) relatam que uma visita ao aterro sanitário de Curitiba, com estudantes do $6^{\circ}$ ano do Ensino Fundamental, proporcionou uma reflexão a respeito da quantidade de geração de resíduo diária, o

R. gest. sust. ambient., Florianópolis, v. 10, n. 2, p. 209-229, jun. 2021. 
tratamento de chorume, o tempo de vida útil do aterro e sobre a falta de conscientização e sensibilização a respeito da separação correta dos materiais.

A partir de um plano adequado de gerenciamento, todos os resíduos do município poderiam receber um destino final adequado, evitando-se danos ao meio ambiente e contribuindo para melhor qualidade de vida da população. Segundo informações da SAMAP, recentemente, no aterro sanitário do município, iniciou-se a construção de um galpão para separação e acondicionamento dos resíduos recicláveis, mas ainda está em fase de acabamento, sem funcionamento. Além disso, há galhos de árvores e entulhos de construção civil que não são destinados ao aterro sanitário ou para o catador de recicláveis. Esses resíduos são depositados em um terreno do município denominado área de transbordo, que ainda está em processo de regularização pelo IAP.

Esses dados corroboram com algumas citações dos moradores de Perobal PR quando questionados se encontram resíduos dispostos em locais inadequados. Entre os 20 entrevistados, destacam-se as informações coletadas: "já vi muito lixo em terreno baldio e bueiros"; "já vi muito no meu bairro Jardim Araucária as pessoas jogam muito entulho beirando um pasto próximo, dá até dó"; "vejo na cidade toda"; "vejo nas próprias ruas de Perobal, mas o que mais me chama a atenção é nas encostas das estradas rurais do município, a coleta de lixo não chega nas chácaras, sítios e fazendas, assim muitos queimam seus lixos e até mesmo descartam em estradas, uma cultura que a meu ponto de vista tem que mudar"; "já vi muita coisa sendo jogada por pedestres"; "sim, eu vi em vários lugares como estrada de terra, terrenos e em beira de rios"; "já vi sim, para fora do aterro e nas estradas indo para estradas rurais". No Brasil, mesmo não atingindo sua área total de abrangência, a coleta seletiva tem aumentado gradativamente nos municípios (CEMPRE, 2019). Contudo, em Perobal - PR observou-se que ainda há muito a ser melhorado nesse aspecto, principalmente promovendo processos de EA crítica. De acordo com Marques e Xavier (2019) "um indivíduo que possui a capacidade de analisar e discutir problemas inteligente e racionalmente, sem aceitar, de forma automática, suas próprias opiniões ou opiniões alheias, é um indivíduo dotado de senso crítico".

\subsection{Coleta Seletiva}

De acordo com dados obtidos na Secretaria de Agricultura e Meio Ambiente de Perobal (SAMAP), os resíduos sólidos orgânicos e rejeitos do município são

R. gest. sust. ambient., Florianópolis, v. 10, n. 2, p. 209-229, jun. 2021. 
recolhidos de segunda à sexta-feira, tanto no perímetro urbano quanto no distrito e na vila rural, sendo encaminhados ao aterro sanitário municipal. A coleta seletiva também é realizada pela prefeitura municipal, como determina a PNRS (BRASIL, 2010). Isso ocorre nas terças e quintas-feiras na cidade, distrito e vila rural, destinando os produtos a um catador de recicláveis do município. Segundo Silva e Marcomin (2020), os catadores participam consideravelmente da gestão dos RSU no Brasil e, apesar de muitos ainda não serem valorizados e trabalharem na informalidade, uma grande quantidade de resíduos são inseridos novamente no processo produtivo.

A coleta regular de RSU em Perobal - PR atende $100 \%$ da população, fato relatado pela SAMAP e confirmado por todos os moradores que contribuíram respondendo ao questionário. O caminhão coletor e compactador recolhe, mensalmente, aproximadamente 86,13 toneladas de RSU que são destinados ao aterro sanitário, resultando, em média, 0,47 $\mathrm{kg} \mathrm{dia}^{-1}$ habitante $^{-1}$ superando a média nacional, que em 2018, foi de 0,380 kg dia-1 habitante-1 (ABRELPE, 2019).

No ano de 2016, em Perobal - PR, em média, mensalmente, foram coletadas aproximadamente 76,126 toneladas de RSU, encaminhados ao aterro sanitário, segundo dados da Prefeitura Municipal (OLIVEIRA; PIRES; NUNES, 2016). Diante disso, observa-se um aumento de $11,6 \%$ de produção de RSU coletados no município em apenas três anos, de 2016 a 2019. Segundo dados da SAMAP, em 2019, a coleta seletiva do município de Perobal - PR recolheu, mensalmente, uma quantidade média de 15,13 toneladas (aproximadamente 18\% do total de RSU) de material reciclável (Figura 1). No entanto, apenas entre 50 e 60\% dos materiais recicláveis foram separados, mas esse número já foi maior, chegando a $70 \%$. Tal informação permite inferir que, entre os $82 \%$ (71 toneladas) restantes de RSU de Perobal - PR (Figura 1) há muito material reciclável misturado com resíduos orgânicos e rejeitos.

R. gest. sust. ambient., Florianópolis, v. 10, n. 2, p. 209-229, jun. 2021. 
Figura 1 - Toneladas de RSU recolhidos mensalmente pela coleta seletiva em Perobal - PR, no ano de 2019.

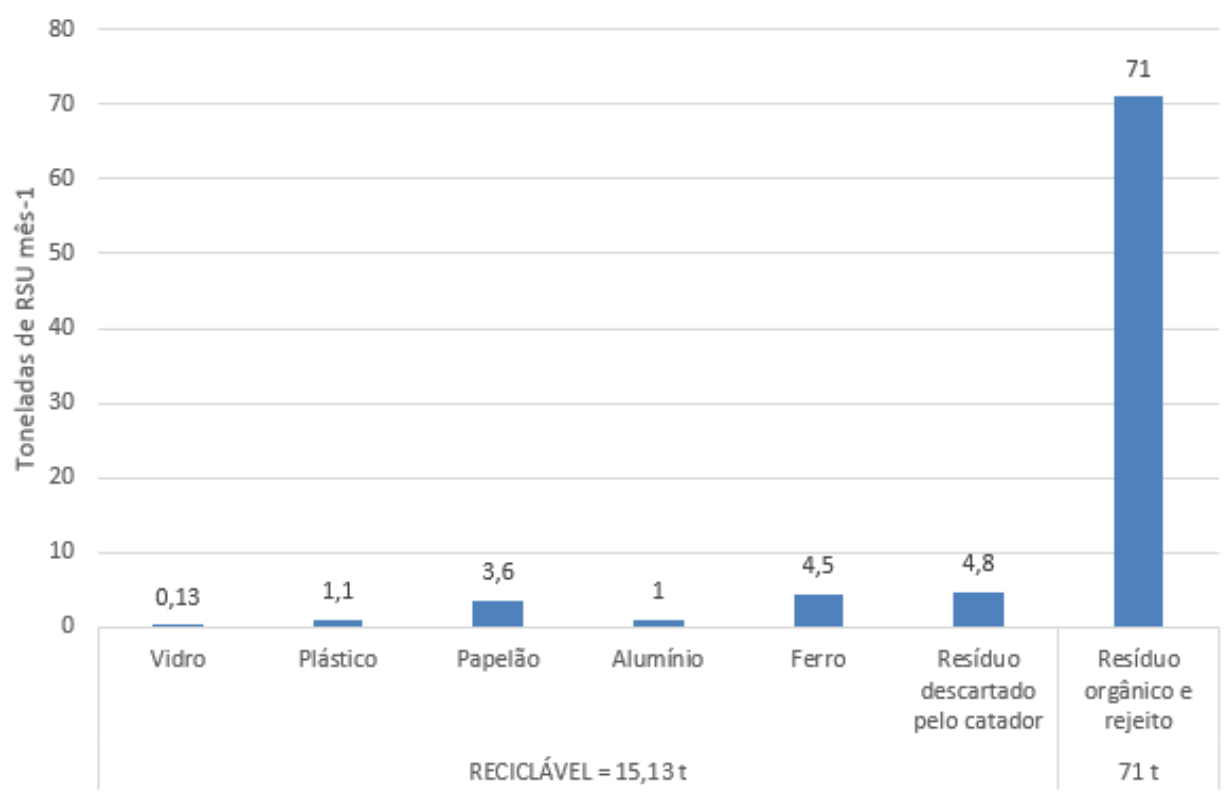

Fonte: Elaborado pelas autoras a partir de dados fornecidos pela SAMAP (2019).

Durante a entrevista, o catador, responsável pela destinação final dos RSU recicláveis do município, relata que as pessoas não sabem separar os resíduos, fato que resulta em maior tempo para segregação e perda de materiais que poderiam ser reciclados. Ele cita "faltam informações para a população em geral". Essa característica está de acordo com a Associação Brasileira de Empresas de Limpeza Pública e Resíduos Especiais, revelando que $75 \%$ dos brasileiros não separam seus resíduos em casa. Segundo a associação, uma das possíveis razões é a falta de informação, já que em uma de suas pesquisas $66 \%$ dos entrevistados afirmaram saber pouco ou nada a respeito de coleta seletiva. Ademais, citam que menos da metade da população sabe que alumínio, papel e PET são materiais recicláveis (ABRELPE, 2019).

O fato relatado pelo catador foi confirmado nas respostas do questionário aplicado a uma amostra da população, em que $92 \%$ dos pesquisados afirmam fazer a separação do resíduo reciclável, porém $90 \%$ destes não souberam explicar como fazem a separação e qual a importância desta ação. Entre os 20 entrevistados, percebe-se que alguns moradores se preocupam com a destinação final correta dos resíduos a partir das seguintes respostas: "acho bem importante separar, pois acredito que a quantidade de lixo nos aterros sanitários diminuem"; "separo o orgânico do reciclado, porém não separo por material, acho importante não misturar lixo reciclado

R. gest. sust. ambient., Florianópolis, v. 10, n. 2, p. 209-229, jun. 2021. 
com material orgânico"; "sempre separo para deixar tudo organizado"; "separo para facilitar o trabalho dos recicladores"; "separo para facilitar o processo de reciclagem, consequentemente ajudando na preservação do meio ambiente"; "separo por causa do meio ambiente e das pessoas que trabalham com reciclagem"; "separo porque fica mais fácil pra reaproveitar"; "separo principalmente por ter consciência da importância da separação dos resíduos”. As citações demonstram que, apesar da carência de informação de conceitos e da forma correta de separação dos RSU, as pessoas possuem boa intenção e poderiam contribuir positivamente no gerenciamento de RSU, a partir de processos de educação ambiental.

Segundo a SAMAP e o catador, os RSU recicláveis coletados em Perobal - PR são armazenados em um galpão particular até sua comercialização. Vale destacar que nem todo material reciclável recolhido na coleta seletiva possui sua destinação final correta. O catador aproveita apenas o que tem valor comercial (plástico, papelão, alumínio e ferro), correspondendo a aproximadamente $67 \%$ do total separado e apenas $12 \%$ do volume total de RSU recolhido no município. O restante, $31 \%$ do material recolhido (5,5\% do volume total de RSU), ele descarta (Figura 1) e encaminha novamente ao aterro sanitário. Ele relata: "não compensa separar um material por apenas três centavos o quilo". Essa rejeição dos RSU sem valor comercial provoca desperdício de material e aumento da quantidade de resíduos que vão para o aterro sanitário. Nesse sentido, Sanchez (2003) relata que os catadores ainda não se reconhecem como importantes agentes na gestão dos RSU. Diante disso, por meio de processos de EA, é preciso valorizar a profissão do catador estreitando laços entre ele e a população local, entre ele e o ambiente, fazendo-o reconhecer seu papel na sociedade, bem como seu lugar no mundo (SILVA; MARCOMIN, 2020). Assim, o catador poderia entender sua função de agente transformador da população, ensinando e aprendendo, aumentando sua autoestima e seu sentido de pertencimento (PINHEL, 2013).

Além disso, o vidro, material não encaminhado ao catador, corresponde a aproximadamente $0,8 \%$ do material separado $(0,15 \%$ do volume total de RSU coletado), cerca de 1,5 toneladas ao ano. Esse vidro é armazenado e encaminhado para o município de Pérola - PR (distante 34,3 km de Perobal - PR) uma vez por ano. De lá, é transportado ao estado de São Paulo para sua reciclagem. Assim, o alto custo com transporte e a ausência de processos de reciclagem de vidro próximos ao município, resultam em uma grande quantidade de garrafas e outros resíduos de vidro

R. gest. sust. ambient., Florianópolis, v. 10, n. 2, p. 209-229, jun. 2021. 
dispostos inadequadamente no ambiente. No Brasil, aproximadamente 1.332,827 toneladas de resíduos de vidro de embalagem são geradas por ano, correspondente a $2 \%$ dos RSU, sendo que $20 \%$ desse total são descartados indevidamente (ABRELPE, 2019).

No aterro sanitário, um funcionário da prefeitura de Perobal - PR tenta separar o material que o catador rejeita. Todavia, encontra o mesmo problema já relatado pelo catador, o material reciclável misturado com o orgânico e rejeitos, dificultando a segregação dos produtos. Nesse sentido, a destinação final ambientalmente adequada de todos os resíduos, prevista na PNRS, não ocorre em Perobal - PR, podendo causar danos ou riscos à saúde pública além de impactos ambientais adversos (BRASIL, 2010). Como exemplo de risco à saúde pública destaca-se a proliferação do mosquito Aedes aegypti, vetor transmissor de dengue (MOL et al., 2020). Além disso, o próprio catador pode sofrer contaminação e danos à sua integridade física a partir do manuseio dos resíduos mal acondicionados, podendo se tornar portador e transmissor de doenças (LUND; ALFERS; SANTANA, 2016).

Diante da ausência de separação correta dos RSU coletados no município, pode-se inferir que a quantidade de rejeitos e resíduos orgânicos (82\%) e material reciclável (18\%) podem estar distantes da realidade. Todos os dados fornecidos pela SAMAP foram apenas estimados. De acordo com Zago e Barros (2019) existe pouca informação sobre a geração e destinação da fração orgânica no Brasil, já que os estudos de composição gravimétrica não ocorrem com frequência. Agostinho et al. (2013) relatam que nas cidades com maior grau de industrialização, como São Paulo por exemplo, a porcentagem de resíduos orgânicos coletados ainda é muito alta (57,5\%), podendo representar separação inadequada. No Brasil, há significativa fração de RSU composta por materiais orgânicos, representando mais de 50\% do total coletado (IBGE, 2010).

Estudos da ABRELPE mostram que, em 2018, a média nacional de RSU gerados foi de 79 milhões de toneladas ( 6.583 .333 toneladas por mês), $1 \%$ a mais que no ano anterior. Dessa quantia, $92 \%$ foram coletados e $8 \%$ não foram recolhidos pelos serviços de coleta. Vale ressaltar que, dentro dessa quantidade de RSU no Brasil, cerca de 43,3 milhões de toneladas foram destinados aos aterros sanitários e aproximadamente 29,5 milhões de toneladas foi parar em lixões ou aterros controlados, que não possuem sistemas e medidas necessárias contra danos ao meio ambiente (ABRELPE, 2019).

R. gest. sust. ambient., Florianópolis, v. 10, n. 2, p. 209-229, jun. 2021. 
Em Perobal - PR, em torno de 75,8 toneladas de RSU (4,8 descartadas pelo catador + 71 de rejeitos e resíduos orgânicos) foram destinados ao aterro sanitário mensalmente em 2019 (Figura 1). Considerando-se que no local não há processo de compostagem e que a quantidade de resíduos que poderiam ser reciclados e foi descartado, o tempo de vida útil do local pode ser comprometido. Figueiredo et al. (2019) relatam que a compostagem converte resíduos biodegradáveis em matéria orgânica higienizada e estabilizada, podendo ser utilizada como fertilizante na agricultura e em hortas domésticas. Segundo os autores, após a conclusão deste processo, a pilha de resíduos orgânicos é reduzida para aproximadamente $50 \%$ do seu volume original devido aos processos aeróbicos e anaeróbicos realizados pelos microrganismos. Pela sua valiosa composição de nutrientes, a compostagem tornase uma alternativa eficiente, com baixo custo, que pode minimizar problemas ambientais e de saúde criados pela disposição inadequada dos resíduos orgânicos (HECK et al., 2013).

Além do exposto, pelo custo com transporte, a maioria dos comércios não recolhe certos tipos de resíduos como pilhas, baterias, pneus, lâmpadas fluorescentes, óleos lubrificantes, embalagens e produtos eletroeletrônicos, inviabilizando a logística reversa. Nesse contexto, apenas $9 \%$ dos pesquisados descartam corretamente lâmpadas, baterias e pilhas em suas residências. Estes armazenam o material e, posteriormente, levam para a cidade de Umuarama - PR (distante 17,7 km), onde as empresas recebem para a logística reversa.

Ainda sobre esta questão, entre os $91 \%$ dos pesquisados que não realizam a ação correta, percebeu-se que a maioria (90\%) não sabia que estava agindo errado. Essa constatação foi feita a partir de alguns relatos dos pesquisados, como: "separo para a reciclagem"; "corto um litro descartável coloco vidros, lâmpadas, pilhas e um bilhete escrito vidros"; "coloco uma identificação para eles saberem o que é"; "jogo na fossa"; "coloco separado, dentro do lixo comum".

Entre os pesquisados que não destinam corretamente as pilhas, lâmpadas e baterias, 10\% justificaram que tem consciência de que está agindo de forma errada, conforme as seguintes observações: "coloco dentro de uma caixa e mando para o lixo, gostaria de saber se existe um ponto específico em nossa cidade para o descarte de pilhas e lâmpadas, tenho consciência que o descarte destes materiais tem que ser feito de forma diferente"; "jogo no lixo comum porque não tenho onde descartar, mas sei que não é correto"; "essa questão é uma deficiência gravíssima em nosso país,

R. gest. sust. ambient., Florianópolis, v. 10, n. 2, p. 209-229, jun. 2021. 
infelizmente por não ter uma coleta adequada acabo descartando junto ao lixo reciclável". Diante disso, além do descumprimento da legislação pelos estabelecimentos de Perobal - PR que não recolhem o material, não há como realizar a logística reversa sem o desenvolvimento de processos de EA, pois ela não pode ocorrer se os resíduos não forem separados corretamente (DOMINGUES; GUARNIERI; STREIT, 2016).

Nesse contexto, Jardim, Yoshida e Machado Filho (2012) reconhecem que a PNRS deve atuar simultaneamente com a Política Nacional de Educação Ambiental, tornando a EA um dos seus instrumentos e requisito dos planos municipais de gestão integrada de RSU, com a participação de diversos atores. Assim, além de um sistema de gerenciamento de RSU mais eficiente em Perobal - PR, torna-se necessário estimular a consciência ambiental da população, conforme recomenda Deus, Battistelle e Silva (2017).

Além disso, para minimizar essa problemática, o poder público precisa exigir e fiscalizar o plano de gerenciamento de resíduos sólidos (PGRS) das empresas. Eles devem ser elaborados nos estabelecimentos comerciais e de prestação de serviços que gerem algum tipo de resíduo perigoso ou que, mesmo classificado como não perigoso, devido à sua natureza, composição ou volume, não seja equiparado aos resíduos domiciliares pelo poder público municipal (BRASIL, 2010). Em Perobal-PR, não há relatos dessa exigência e, tão pouco, da fiscalização. Vale ressaltar que esse documento pode ser exigido também pelos órgãos ambientais, para regularização dos estabelecimentos em relação ao licenciamento, prevenção e minimização da geração de resíduos a partir dos princípios (não geração, redução, reutilização e reciclagem), além do manejo dos RSU (DESSBESELL; BERTICELLI, 2019).

Diante do exposto, é possível inferir que, a partir da exigência do PGRS e sua atualização anualmente, os RSU do município de Perobal - PR poderiam ser destinados corretamente de acordo com suas características (incineração, reciclagem, reutilização, tratamento, compostagem), com normas estabelecidas no documento. Ademais, com o PGRS implantado nas empresas, processos de EA estariam garantidos a todos os geradores de diferentes resíduos. Nessa direção, Dessbesell e Berticelli (2019) explicam que o PGRS traz resultados a médio e longo prazo, ele requer realimentação contínua, sempre bem equacionada, discutida e assimilada por seus responsáveis. Os autores recomendam, antes de tudo, a mudança de atitudes. Tais mudanças só podem ocorrer a partir de uma EA

R. gest. sust. ambient., Florianópolis, v. 10, n. 2, p. 209-229, jun. 2021. 
crítica/decolonial, organizada a partir de pequenos grupos que lutam em defesa da vida, a partir de movimentos sociais, fundamentando a luta socioambiental (STORTTI; SANCHEZ-PEREIRA, 2017). A EA só é efetiva quando a abordagem possibilita uma maior compreensão do fenômeno, apurando as relações humanas no ambiente, incorporando práticas sustentáveis (MARCOMIN; SATO, 2016).

\section{CONSIDERAÇÕES FINAIS}

Neste estudo, numa dinâmica contínua da teoria para os dados e vice-versa, as categorias qualidade de vida, aterro sanitário e coleta seletiva tornaram-se claras e apropriadas aos propósitos do estudo. No município de Perobal - PR observou-se que a PNRS ainda não é aplicada integralmente, necessitando de uma reformulação do planejamento da gestão de RSU para contemplar todos os seus aspectos.

Destaca-se a necessidade da exigência de implantação e fiscalização do PGRS nos estabelecimentos, conforme o Art. 14, inciso VI da Lei no 12.305, de 2 de agosto de 2010. Além disso, o aterro sanitário do município precisa de adequações, com melhor organização dos resíduos recicláveis e inserção do o processo de compostagem dos resíduos orgânicos.

Outrossim, é urgente a ampliação dos processos de educação ambiental no ensino formal e não formal. A partir dessa iniciativa, a comunidade pode ser sensibilizada, tornando-se mais responsável pelos seus resíduos, com possibilidade de melhorias no meio ambiente e na qualidade de vida da população. Os resíduos encaminhados para reciclagem e compostagem podem gerar emprego e renda, além de incentivar novos estudos e pesquisas, influenciando diretamente na melhoria dos indicadores de qualidade de vida pesquisados (GINI, PIB e IDH).

\section{REFERÊNCIAS}

AGOSTINHO, F.; ALMEIDA, C. M. V.; BONILLA, S. H.; SACOMANO, J. B.; GIANNETTI, B.F. Urban solid waste plant treatment in Brazil: is there a net emergy yield on the recovered materials? Resources, Conservation and Recycling, v. 73, p. 143-155, 2013.

ASSOCIAÇÃO BRASILEIRA DE EMPRESAS DE LIMPEZA PÚBLICA E RESÍDUOS ESPECIAIS (ABRELPE). (2020) Panorama dos Resíduos Sólidos no Brasil 2011. São Paulo: ABRELPE. Disponível em: http://abrelpe.org.br/panorama. Acesso em: 18 jun. 2021.

ASSOCIAÇÃO BRASILEIRA DE NORMAS TÉCNICAS (ABNT). (1997) NBR 13896:

Aterros de resíduos não-perigosos - critérios para projeto, implantação e

R. gest. sust. ambient., Florianópolis, v. 10, n. 2, p. 209-229, jun. 2021. 
operação. Rio de Janeiro: ABNT. Disponível em:

https://www.abntcatalogo.com.br/norma.aspx?|D=4829/. Acesso em 18 nov. 2019.

BAGNOLO, C. M. Business community and environment: some considerations about environmental education in the school space. Ciência \& Educação, v. 16, n. 2, p. 401-413, 2010.

BARDIN, L. Análise de conteúdo: edição revisada e ampliada. São Paulo: Edições 70, 2016, $223 \mathrm{p}$.

BESEN, G. R.; RIBEIRO, H.; GUNTHER, W. M. R.; JACOBI, P. R. Selective waste collection in the São Paulo metropolitan region: impacts of the national solid waste policy. Ambiente \& Sociedade, n. 3, p. 253-272, 2014.

BEZERRA, F. C.; SOARES, B. M.; LIMA, J. C. F.; LOPES, M. B.; SILVA, E. J. Educação ambiental para a sustentabilidade: a redução do lixo orgânico na comunidade acadêmica por meio do processo de compostagem. Revista Multidisciplinar e de Psicologia, v. 13, n. 43, p. 1121-1131, 2019.

BOHRER, R. E. G.; LANGNER, C. H.; LARA, D. M.; SOUZA, E. L.; BISOGNIN, R. P.; GUERRA, D.; SILVA, D. M. Avaliação da disposição irregular de resíduos sólidos no município de Santo Augusto/RS. Revista Gestão \& Sustentabilidade Ambiental, v. 8, n. 2, p. 175-197, 2019.

BRASIL. Senado Federal. Constituição da República Federativa do Brasil. Brasília: Coordenação de Edições Técnicas, 2016. 496 p.

BRASIL. Senado Federal. Lei № 9.795, de 27 de abril de 1999: Dispõe sobre a educação ambiental, institui a Política Nacional de Educação Ambiental e dá outras providências. Diário Oficial da República Federativa do Brasil, Brasília, DF, n. 79, Seção 01, pág. 01.

BRASIL. Lei № 12.305, de 2 de agosto de 2010. Institui a Política Nacional de Resíduos Sólidos; altera a Lei no 9.605, de 12 de fevereiro de 1998; e dá outras providências. Diário Oficial da República Federativa do Brasil, Brasília, DF, 2 ago. 2010, $189^{\circ}$ da Independência e $122^{\circ}$ da República.

BRASIL. Ministério do Meio Ambiente. Resolução CONAMA № 401 de 04 de novembro de 2008. Estabelece os limites máximos de chumbo, cádmio e mercúrio para pilhas e baterias comercializadas no território nacional e os critérios e padrões para o seu gerenciamento ambientalmente adequado, e dá outras providências. Brasília: Senado Federal, 2008.

CAMPOS, H. K. T. Renda e evolução da geração per capita de resíduos sólidos no Brasil. Engenharia Sanitária e Ambiental, v. 17, n. 2, p. 171-180, 2012.

CANTERO DORSA, A. C. C.; CONSTANTINO, M. A. Convergências entre indicadores de desenvolvimento local, índice de desenvolvimento humano e índice de Gini. Revista Contribuiciones a las Ciencias Socilaes, jul. 2018.

CARVALHO, I. C. M. Educação ambiental: a formação do sujeito ecológico. São Paulo: Cortez, 2004.

COMPROMISSO EMPRESARIAL PARA RECICLAGEM (CEMPRE). Artigos e Publicações. São Paulo: CEMPRE, 2019. Disponível em: http://cempre.org.br/. Acesso em 05 out. 2019.

R. gest. sust. ambient., Florianópolis, v. 10, n. 2, p. 209-229, jun. 2021. 
DESSBESELL, G. C.; BERTICELLI, R. Implementação do plano de gerenciamento de resíduos sólidos em centro de formação profissional - nota técnica. Revista Gestão \& Sustentabilidade Ambiental, v. 8, n. 1, p. 947-972, 2019.

DEUS, R. M.; BATTISTELLE, R. A. G.; SILVA, G. H. R. Scenario evaluation for the management of house hold solid waste in small Brazilian municipalities. Clean Technologies Environmental Policy, v. 19, n.1, p. 205-214, 2017.

DIAS, S. G. O desafio da gestão de resíduos sólidos urbanos. Revista Sociedade e Gestão, v. 11, n. 1, p. 16-20, 2012.

DOMINGUES, G. S.; GUARNIERI, P.; STREIT, J. A. C. Princípios e Instrumentos da Política Nacional de Resíduos Sólidos: Educação Ambiental para a Implementação da Logística Reversa. Revista em Gestão, Inovação e Sustentabilidade, v. 2, n. 1, p. 191-215, 2016.

FIGUEIREDO, R. T.; BRITO, M. J. C.; SANTOS, P. H. C.; SOARES, C. M.; BURLE, E. C. Monitoring of small scale composting. Semioses, v. 13, n. 3, p. 98-107, 2019.

GIACCOM-RIBEIRO, B. M.; MENDES, C. A. B. Avaliação de parâmetros na estimativa da geração de resíduos sólidos urbanos. Revista Brasileira de Planejamento e Desenvolvimento, v. 7, n. 3, p. 422-443, 2018.

GOUVEIA, N. Resíduos sólidos urbanos: impactos socioambientais e perspectiva de manejo sustentável com inclusão social. Ciência \& Saúde Coletiva, v. 17, n. 6, p. 1503-1510, 2012.

HECK, K. Temperatura de degradação de resíduos em processo de compostagem e qualidade microbiológica do composto final. Revista Brasileira de Engenharia Agrícola e Ambiental, v. 17, n 1, p. 54-59, 2013.

INSTITUTO BRASILEIRO DE GEOGRAFIA E ESTATÍSTICA (IBGE). (2010)

Pesquisa nacional por amostra de domicílios (PNAD). Rio de Janeiro: IBGE. Disponível em: https://www.ibge.gov.br/. Acesso em: 30 abr. 2020.

INSTITUTO BRASILEIRO DE GEOGRAFIA E ESTATÍSTICA (IBGE). (2018) PIB, Produto Interno Bruto 2018. Rio de Janeiro: IBGE. Disponível em:

https://www.ibge.gov.br/explica/pib.php. Acesso em: 20 nov. 2019.

INSTITUTO BRASILEIRO DE GEOGRAFIA E ESTATÍSTICA (IBGE). (2019) PIB, Produto Interno Bruto $2^{\circ}$ trimestre de 2019. Rio de Janeiro: IBGE. Disponível em https://agenciadenoticias.ibge.gov.br/agencia-sala-de-imprensa/2013-agencia-denoticias/releases/25298-pib-varia-0-4-no-2-trimestre-de-2019/. Acesso em: 20 nov. 2019.

INSTITUTO PARANAENSE DE DESENVOLVIMENTO ECONÔMICO E SOCIAL (IPARDES). (2019) Perfil avançado dos municípios. Curitiba: IPARDES. Disponível em: http://www.ipardes.gov.br/index.php?pg conteudo=1\&cod conteudo=29/. Acesso em: 20 out. 2019.

INSTITUTO DE PESQUISA APLICADA (IPEA). (2004) O que é? Índice de Gini. Brasília: IPEA. Disponível em:

http://desafios.ipea.gov.br/index.php?option=com content\&id=2048: catid=28.

Acesso em 21 nov. 2019.

R. gest. sust. ambient., Florianópolis, v. 10, n. 2, p. 209-229, jun. 2021. 
JARDIM, A.; YOSHIDA, C.; MACHADO FILHO, J. V. Política Nacional, gestão e gerenciamento de resíduos sólidos. 1 ed. Barueri: Ed. Manole, 2012, 77 p.

KAUARK, F.; MANHÃES, F. C.; MEDEIROS, C. H. Metodologia da pesquisa: guia prático. Itabuna: Via Litterarum, 2010, $89 \mathrm{p}$.

LUND, F.; ALFERS, L.; SANTANA, V. Towards an inclusive occupational health and safety for informal workers. Journal of Environmental and Occupational Health Policy, v. 26, n. 2, p. 190-207, 2016.

MACEDO, F. C.; PORTO, L. R. Dinâmica regional brasileira: uma análise com base nos dados do PIB municipal (2002-2015). Revista de Economia Regional Urbana e do Trabalho, v. 6, n. 2, p. 52-69, 2018.

MARCOMIN, F. E.; SATO, M. Percepção, Paisagem e Educação Ambiental: uma investigação na região litorânea de Laguna-SC, Brasil. Educação em Revista [online], v. 32, n. 2, p.159-186, 2016.

MARQUES, R.; XAVIER, C. R. Análise das inferências na construção do senso crítico numa sequência didática na Educação Ambiental. Revista Cocar, edição especial, n. 5, p. 51-94, 2019.

MOL, M. P. G.; QUEIROZ, J. T. M.; GOMES, J.; HELLER, L. Gestão adequada de resíduos sólidos como fator de proteção na ocorrência da dengue. Revista

Panamericana de Salud Pública, n. 44, e22, p. 1-9, 2020.

NEDER, H. D. Análise de Indicadores Sociais Utilizando o Stata. Uberlândia: Ed. UFU, 2013, $154 \mathrm{p}$.

OLIVEIRA, D. F.; PIRES, R. S.; NUNES, I. H. S. Avaliação do Índice de Qualidade do Aterro Sanitário no Município de Perobal - PR. 2016. Trabalho de Conclusão do Curso de Engenharia Civil, Umuarama: Ed. Unipar, 2016, 17 p. Disponível em: https://tcc.unipar.br/files/tccs/f25373892977a36904ca44f41682b185.pdf. Acesso em 05 set. 2019.

ORGANIZAÇÕES DAS NAÇÕES UNIDAS (ONU). (2019) Banco Mundial alerta para desigualdades de renda no Brasil. Brasília: ONU. Disponível em: https://nacoesunidas.org/banco-mundial-alerta-para-desigualdades-de-renda-nobrasil/. Acesso em: 21 nov. 2019.

PEROBAL, Prefeitura Municipal. Lei Complementar $\mathbf{N}^{\circ}$ 045, de 30 de novembro de 2011. Dispõe sobre o Plano Diretor do Município de Perobal, estabelece diretrizes e proposições para o planejamento, desenvolvimento e gestão do território do município. Perobal: Prefeitura Municipal, 2011. Disponível em: http://perobal.pr.gov.br/. Acesso em 03 ago. 2019.

PEROBAL, Prefeitura Municipal. Lei Complementar № 117, de 27 de dezembro de 2018. Atualiza o código de obras do município de Perobal, Estado do Paraná e dá outras providências. Perobal: Prefeitura Municipal, 2018. Disponível em: http://perobal.pr.gov.brl. Acesso em 03 ago. 2019.

PINHEL, J. R. (Org.). Do lixo à cidadania: guia para a formação de cooperativas de catadores de materiais recicláveis. São Paulo: Editora Peirópolis, 2013.

PINTO, A. E. M.; NASCIMENTO, R. M. Sustentabilidade e precaução: uma avaliação do plano municipal de gerenciamento de resíduos de Macaé referenciados na

R. gest. sust. ambient., Florianópolis, v. 10, n. 2, p. 209-229, jun. 2021. 
Política Nacional de Resíduos Sólidos. Revista de Direito da Cidade, v. 10, n. 1 p. 78-94, 2017.

PRODANOV, C. C.; FREITAS, E. C. Metodologia do Trabalho Científico: Métodos e técnicas da pesquisa e do trabalho acadêmico. 2 ed. Novo Hamburgo: Ed.

Feevale, 2013, 227 p.

PROGRAMA DAS NAÇÕES UNIDAS PARA O DESENVOLVIMENTO (PNUD). (2014) Relatório do Desenvolvimento Humano. Sustentar o Progresso Humano: Reduzir as Vulnerabilidades e Reforçar a Resiliência. Nova Yorque: PNUD.

Disponível em: http://hdr.undp.org/sites/default/files/hdr2014 pt web.pdf/. Acesso em 10 out. 2019.

RAUBER, M. E. Apontamentos sobre a política nacional de resíduos sólidos, instituída pela lei federal № 12.305, de 02.08.2010. Revista Eletrônica em Gestão, Educação e Tecnologia Ambiental, v. 4, n. 4, p. 01-24, 2011.

RODRIGUES, L. C.; MARIN, S. R.; ALVARENGA, S. M. Reciclagem de resíduos sólidos urbanos em Florianópolis - SC: um estudo de caso. Revista Gestão \& Sustentabilidade Ambiental, v. 6, n. 1, p. 470 - 486, 2017.

SANCHEZ, E. Catador X Agente Ambiental. Revista Limpeza Pública, São Paulo, n. 60, p.12, mar. 2003.SANTIAGO, L. S.; DIAS, S. M. F. Matriz de indicadores de sustentabilidade para a gestão de resíduos sólidos urbanos. Engenharia Sanitária e Ambiental, v. 17, n. 2, p. 203-212, 2012.

SCHNEIDER, D. M.; RIBEIRO, W. A.; SALOMONI, D. Orientações Básicas para a Gestão Consorciada de Resíduos Sólidos. In: OLIVEIRA, N. P.; HELOU, L. D. R.; ANTERO, S. A. (orgs.). Fundação Instituto para o Fortalecimento das Capacidades Institucionais - IFCl; Agência Espanhola de Cooperação Internacional para o Desenvolvimento - AECID; Ministério do Planejamento, Orçamento e Gestão MPOG.Brasília: Ed IABS, 2013, 220 p.

SILVA, R. C.; MARCOMIN, F. E. Desvelamento da percepção dos catadores de materialreciclável: possibilidades à resistência. Ensino, Saúde e Ambiente, n. especial, p. 310-330, 2020.

STORTTI, M. A.; SANCHEZ-PEREIRA, C. S. Reflexões sobre a Educação Ambiental Crítica em um Grupo de Pesquisa: um estudo de caso do Geasur. AS \& T, v. 5, n. 1, p. 15-21, 2017.

ZAGO, V. C. P.; BARROS, R. T. V. Gestão dos resíduos sólidos orgânicos urbanos no Brasil: do ordenamento jurídico à realidade. Engenharia Sanitária e Ambiental, v. 24, n. 2, p. 219-228, 2019.

ZANATA, V. M, SOBRINHO, D.G.S. RODRIGUES, C. S. Proposta de melhorias no Sistema de Manejo e Disposição dos Resíduos Sólidos para Pequenas Comunidades (Proresol). $4^{\circ}$ Caderno de Pesquisa em Engenharia de Saúde Pública. Fundação Nacional de Saúde (Funasa). Brasília. 2010.

R. gest. sust. ambient., Florianópolis, v. 10, n. 2, p. 209-229, jun. 2021. 